\title{
$\operatorname{RDS}\left({ }^{\circ}\right)$
}

Revista Desenvolvimento Social

\author{
Vol. 27, n. 1, jan/jun, 2021
} ISSN: 2179-6807 (online)

\section{REFLEXÕES SOBRE O ESPAÇO URBANO NA PANDEMIA, A PARTIR DO BAIRRO MAJOR PRATES, EM MONTES CLAROS-MG}

\author{
Mariana Fernandes Teixeira ${ }^{1}$ \\ Recebido em: 18/04/2021 \\ Aprovado em: 22/06/2021
}

Resumo: O presente trabalho buscou analisar a formação do bairro Major Prates, na cidade de Montes Claros - MG, e suas características contemporâneas, levando em consideração seu caráter paradoxal, intensificado no contexto pandêmico. Por um lado, apresenta uma rede complexa de serviços e comércios, especulação imobiliária e disputas espaciais, por outro, uma articulação do urbano e do rural, revelando tradições e modos astuciosos de construir suas dinâmicas e sociabilidades. $O$ estudo foi realizado a partir de uma combinação metodológica de pesquisa bibliográfica e observação direta. A primeira etapa procurou analisar a articulação do bairro com a cidade, em relação ao planejamento urbano, ressaltando o papel de subcentro e o caráter de resistência presente nas práticas socioespaciais dos citadinos. A observação direta ocorreu em horários e dias diferentes do mês de dezembro de dois mil e vinte, buscando identificar e analisar ações e comportamentos que demonstrem as estratégias de resistência realizadas no âmbito cotidiano, nos espaços que tem interface com a rua. Pretendeu-se, com isso, fomentar reflexões mais críticas sobre o espaço público, pois, além de desempenhar importantes papéis democráticos, é o palco no qual se realiza a vida urbana, o respiro da rotina, o encontro, e, principalmente, a diversidade.

Palavras-chave: Espaço Urbano. Major Prates. Citadinos. Resistência. Pandemia.

\section{REFLECTIONS ON THE URBAN SPACE IN PANDEMIA, FROM THE NEIGHBORHOOD MAJOR PRATES, IN MONTES CLAROS-MG}

Abstract: The present work sought to analyze the formation of the Major Prates neighborhood, in the city of Montes Claros - MG, and its contemporary characteristics, taking into account its paradoxical character, intensified in the pandemic context. On the one hand, it presents a complex network of services and businesses, real estate speculation and spatial disputes, on the other hand, an articulation of urban and rural aspects, revealing traditions and astute ways of building their dynamics and sociability. The study was built with a methodological combination of bibliographic research and direct observation. The first stage sought to analyze the

\footnotetext{
1 Doutoranda em Desenvolvimento Social pelo PPGDS - UNIMONTES; Mestre em Arquitetura e Urbanismo pelo NPGAU - UFMG; Arquiteta e Urbanista pela UFMG; Coordenadora do curso de Arquitetura e Urbanismo na UNIFIPMoc; Professora e orientadora de Trabalho de Graduação nos cursos de Arquitetura e Urbanismo e Engenharia Civil na UNIFIPMoc. E-mail: nanafteixeira@gmail.com. ORCID: https://orcid.org/0000-0003-0883-4889.
} 
articulation of the neighborhood with the city, in relation to urban planning, highlighting the role of sub-center and the character of resistance present in the socio-spatial practices of city dwellers. Direct observation took place at different times and days in the month of December, two thousand and twenty, seeking to identify and analyze actions and behaviors that demonstrate the strategies of resistance performed on a daily basis, in spaces that have an interface with the street. Afterall, it was intended to encourage more critical reflections on the public space, because in addition to playing important democratic roles, it is the stage on which urban life takes place, the breathing of routine, the encounter, and, mainly, diversity.

Keywords: Urban Space. Major Prates. City dwellers. Resistance. Pandemic.

REFLEXIONES SOBRE EL ESPACIO URBANO EN PANDEMIA, DESDE EL BARRIO MAYORES PRATES, EN MONTES CLAROS-MG

Resumen: El presente trabajo buscó analizar la formación del barrio Major Prates, en la ciudad de Montes Claros - MG, y sus características contemporáneas, teniendo en cuenta su carácter paradójico, intensificado en el contexto pandémico. Por un lado, presenta una compleja red de servicios y negocios, especulación inmobiliaria y disputas espaciales, por otro, una articulación de áreas urbanas y rurales, revelando tradiciones y formas astutas de construir su dinámica y sociabilidad. El estudio se realizó a partir de una combinación metodológica de investigación bibliográfica y observación directa. La primera etapa buscó analizar la articulación del barrio con la ciudad, en relación al urbanismo, destacando el papel de subcentro y el carácter de resistencia presente en las prácticas socioespaciales de los habitantes de la ciudad. La observación directa se realizó en diferentes momentos y días del mes de diciembre del dos mil veinte, buscando identificar y analizar acciones y comportamientos que demuestren las estrategias de resistencia que se llevan a cabo en el día a día, en espacios que tienen interfaz con la calle. . Se pretendía, con ello, propiciar reflexiones más críticas sobre el espacio público, pues, además de jugar importantes roles democráticos, es el escenario en el que se desarrolla la vida urbana, el respiro de la rutina, el encuentro y, principalmente, diversidad.

Palabras clave: Espacio urbano. Major Prates. Habitantes de la ciudad. Resistencia. Pandemia.

\section{INTRODUÇÃO}

A pandemia de COVID-19 impacta profundamente a dinâmica das cidades e seu avanço intensifica as contradições expressas no espaço público e nas formas de ocupálo. Nesse sentido, busca-se estabelecer uma relação entre as características do bairro Major Prates, em Monte Claros-MG, e os novos comportamentos percebidos em seu cotidiano, no contexto pandêmico.

Conforme passam-se os anos e suas configurações se alteram, mais evidentes ficam os conflitos e as contradições. Pode-se dizer que há, pelo menos, duas formas de se olhar as cidades. Uma de cima, a partir das lógicas normativas, das leis e do planejamento e outra a partir de baixo, ou dos lados, a partir das pessoas que agem, 
ocupam, modificam, se apropriam dos espaços, transformando-os constantemente. Nessa direção o presente trabalho procura provocar reflexões acerca do espaço urbano no bairro Major Prates, considerando como recorte temporal o segundo semestre de 2020.

Inicia-se esse debate trazendo três observações. a) O bairro Major Prates, principal subcentro da cidade de Montes Claros-MG compreende um conjunto de qualidades que extrapolam as características que o classificam como tal. Sua identidade atípica o coloca em posição de objeto de estudo nessa pesquisa, que procura identificar e analisar o caráter de resistência presente nas formas de apropriação de seus espaços públicos e edificações. b) A partir do pressuposto de que os elementos construídos da cidade contemporânea são decorrentes de uma lógica pré-estabelecida, mercadológica, que dita as demandas a que devem atender, observam-se os bairros que compreendem usos comerciais e de serviços na cidade de Montes Claros-MG. Pela grande oferta de estabelecimentos de serviços, instituições e comércios, e por suas dinâmicas se aproximarem das dinâmicas dos centros principais da cidade, eles recebem a classificação de subcentros. c) O planejamento e as regras urbanas que direcionam o crescimento e a evolução do bairro podem conduzir a uma configuração muito distinta do que se verifica hoje, uma vez que o zoneamento gera ruas e imóveis muito valorizados, tanto financeiramente, quanto pelo potencial construtivo. Questiona-se, com isso, se o bairro conseguirá manter seu caráter identitário, suas territorialidades e suas peculiaridades.

O que se verifica hoje é que, apesar desses potenciais imobiliários e das constantes construções e reformas que surgem a todo momento pelas ruas, as pessoas realizam práticas cotidianas, individuais ou coletivas, nas instâncias públicas e privadas que dão novos significados a esses espaços e edificações. As maneiras de apropriação do bairro apontam para aspectos de resistência, enquanto a tendência é que ocorra uma submissão à dinâmica capitalista contemporânea e fracasso da urbanidade. Em situações cotidianas, a população resgata certas práticas, superadas na maioria dos bairros, como a realização de feiras de rua, a apropriação das calçadas com usos de contemplação e sociabilidade, a manutenção de uma estética associada ao meio rural, dentre outros indícios que serão retratados aqui. 


\section{METODOLOGIA}

Ao traçar esse caminho metodológico, buscaram-se na Arquitetura e Urbanismo e na Antropologia Urbana as perspectivas para se observar a cidade. Essa abordagem interdisciplinar joga luz na camada viva, humana, que se sobrepõe e dá sentido ao locus, ao local geográfico. Para isso, o estudo foi realizado a partir de uma combinação de pesquisa bibliográfica e documental com observação direta.

A primeira etapa buscou fundamentar a articulação do bairro com a cidade, com seu planejamento, ressaltando o papel de subcentro, e o caráter de resistência presente nas práticas socioespaciais dos citadinos. A pesquisa documental buscou a compreensão sobre a formação da cidade, as características do Plano Diretor e a dinâmica de crescimento, tanto da cidade, quanto do bairro, com atenção especial para as interfaces de comércios e espaços públicos.

A observação direta ocorreu em horários e dias diferentes do mês de dezembro de dois mil e vinte, buscando identificar e analisar ações e comportamentos que demonstram as estratégias de resistência realizadas no âmbito cotidiano, nos espaços que tem interface com a rua. O contexto pandêmico interfere na realização de atividades do dia a dia, uma vez que o município tem aplicado regras de segurança e prevenção, como os distanciamentos, a obrigatoriedade do uso de máscaras para proteção, o uso de álcool em gel para desinfecção das mãos, dentre outras medidas. Com esses novos hábitos, a população retoma os espaços públicos e comércios reivindicando maneiras de socializar, ainda que com certas limitações.

Ao sugerir deslocar o olhar da cidade e focar nas pessoas, Agier $(2011$, p. 35) afirma que

O antropólogo encontra na investigação urbana uma fonte inesgotável de problemáticas híbridas e complexas: pode destacar as exclusões e os fechamentos, por um lado, e os encontros e as aprendizagens, por outro, mas pode também aproveitar essa complexidade para procurar o ponto de equilíbrio entre "o sentido do lugar e a liberdade do não lugar".

Dessa forma, as cenas e situações observadas são dotadas de um caráter simbólico muito forte, uma vez que os locais escolhidos pela autora são, talvez, os mais representativos do bairro. Não apenas pela concentração de usos, mas principalmente porque são vias estruturantes, locais de passagem, de referência e grande fluxo. Apesar 
de se verificarem como vias comerciais, a dinâmica das mesmas atrai uma amostra significativa de citadinos, que se aproveitam desse movimento para intensificar a sociabilidade. Assim, foram escolhidos dias aleatórios da semana e uma manhã de domingo para realização das visitas e observações em campo. O pressuposto para o estudo foi trabalhar um olhar de estranhamento e curiosidade, atento aos comportamentos, às novas regras de uso do espaço e de interação com objetos e pessoas, mas também às distorções, transgressões, expressões artísticas, espontâneas e outras formas de interação com espaço público e com o invisível covid-19.

\section{A CIDADE}

A cidade de Montes Claros localiza-se no norte do Estado de Minas Gerais, na bacia do Alto Médio São Francisco, em uma área integrante do domínio do cerrado, de clima tropical semiúmido. O município abrange uma área territorial aproximada de $3.568,941 \mathrm{~km}^{2}$ e sua população estimada para 2016 era de 402.027 habitantes (IBGE, 2010). A cidade, de médio porte, teve sua origem no movimento das bandeiras paulistas, no período colonial, uma vez que constituía um ponto de passagem de tropeiros e comerciantes, que conectava o estado de Minas com a Bahia. No século XIX, conhecida como a capital do sertão mineiro, destacava-se por sua função comercial. Dessa maneira, a cidade seguiu até meados do século $X X$, com a economia baseada no comércio e na agropecuária e população predominantemente residente em área rural (LEITE; PEREIRA, 2005).

O processo de urbanização e expansão territorial de Montes Claros iniciou na década de 1970, em função de uma política desenvolvimentista realizada pelo Estado, que viabilizou a industrialização da região. Devido à sua localização, a cidade passou a ser foco de um intenso fluxo migratório, o que contribuiu para que se consolidasse com um centro polarizador da região do norte de Minas Gerais.

Nesse contexto, é notório o papel da SUDENE (Superintendência de Desenvolvimento do Nordeste), através da qual foram aplicados incentivos fiscais e financeiros do poder público (federal, estadual e municipal). A Superintendência atuou como agente modernizador da estrutura econômico-social e do espaço urbano da 
cidade e da região, marcando a transição de uma cidade Agrário-Mercantil para uma cidade Urbano-Industrial (SILVA, 2008).

O advento da atividade industrial desencadeou uma série de transformações na economia regional, com significativos reflexos na área urbana de Montes Claros. As mudanças que ocorriam no campo acabaram repelindo a população rural, enquanto o poder atrativo da indústria recém-instalada provocava fortes fluxos migratórios para a cidade. Logo, teve início o processo de urbanização de Montes Claros, que se intensificou nas décadas seguintes, conforme demonstrado na Tabela 3. (LEITE; PEREIRA, 2005).

\begin{tabular}{|cccc|}
\hline Ano & Urbana & Rural & Total \\
\hline 1960 & 43.097 & 59.020 & 102.117 \\
\hline 1970 & 85.154 & 31.332 & 116.486 \\
\hline 1980 & 155.483 & 22.075 & 177.558 \\
\hline 1990 & 250.573 & 30.969 & 281.542 \\
\hline 2000 & 289.183 & 17.764 & 306.947 \\
\hline 2010 & 344.427 & 17.488 & 361.915 \\
\hline
\end{tabular}

Tabela 1 - Evolução da população de Montes Claros

Fonte: IBGE. Censos Demográficos: 1960 a 2010

As mudanças ocorridas na cidade, ao ser escolhida para sede de uma área industrial, recebendo indústrias de vários tipos, provocaram alterações tanto em sua estrutura econômica, quanto na esfera social e urbana. Desse modo, em decorrência da intensa urbanização, verificou-se uma expansão do território e de sua periferia. Sobre esse contexto, analisa-se que

A instalação inicial de instituições estatais como o Departamento Nacional de Obras Contra a Seca, a Companhia de Desenvolvimento do Vale do São Francisco e a Superintendência de Desenvolvimento do Nordeste propiciaram por um lado a implantação de infraestrutura necessária à instalação de empresas capitalistas com capital local ou vindos de outras regiões do país, em busca dos financiamentos a juros subsidiados e dos incentivos fiscais e financeiros, por meio do qual tornou possível a reprodução do capital na região. E, por outro lado, em decorrência dos investimentos e financiamentos disponibilizados um processo violento de expropriação territorial dos sitiantes, posseiros e pequenos proprietários, forçando o êxodo rural e o inchamento das cidades e consequente 
concentração fundiária, a chamada modernização conservadora do campo. (COSTA, 2019, p. 234)

Sendo assim, a ampliação da malha urbana não ocorreu de maneira homogênea, nem se submeteu a um planejamento efetivo, gerando um tecido urbano predominantemente horizontalizado e fragmentado. No Mapa 1, pode-se perceber que o crescimento urbano de Montes Claros apresenta um padrão disperso, já que se desenvolveu de forma espontânea. Nesse mapa, o bairro Major Prates se enquadra no período de crescimento da década de 1970.

A partir desse período, a criação do distrito industrial cria um eixo de crescimento para o vetor Norte da cidade, cuja ocupação, até então, se resumia à área central. Os anos 1980 marcam uma significativa expansão territorial para os lados Leste e Sul, e um movimento de preenchimento dos vazios urbanos resultantes da ocupação descontínua. Ressalta-se que a área oeste da cidade, ocupada pela população de renda mais alta, teve um crescimento menos significativo.

Nesse processo, Pereira e Leite (2017) alertam para o papel da especulação imobiliária, ordenador do crescimento urbano, responsável pelos vazios urbanos e responsável pela instalação de infraestrutura de qualidade em pontos específicos. Sua influência acabou por estabelecer uma hierarquia de valorização nas áreas da cidade, controlando o mercado de terras e definindo o local de moradia das classes dominantes e das segregadas. Em Montes Claros, a especulação imobiliária se apresentou como atividade lucrativa e sedutora às famílias tradicionais, atraindo investimentos de grandes pecuaristas da região. Tal fenômeno não encontrou impedimentos na legislação municipal e vem acarretando, até os dias atuais, degradação ambiental, enquanto avança sobre áreas que deveriam estar protegidas, e segregação socioespacial, empurrando a população com menor poder aquisitivo para terras cada vez mais distantes do centro. 


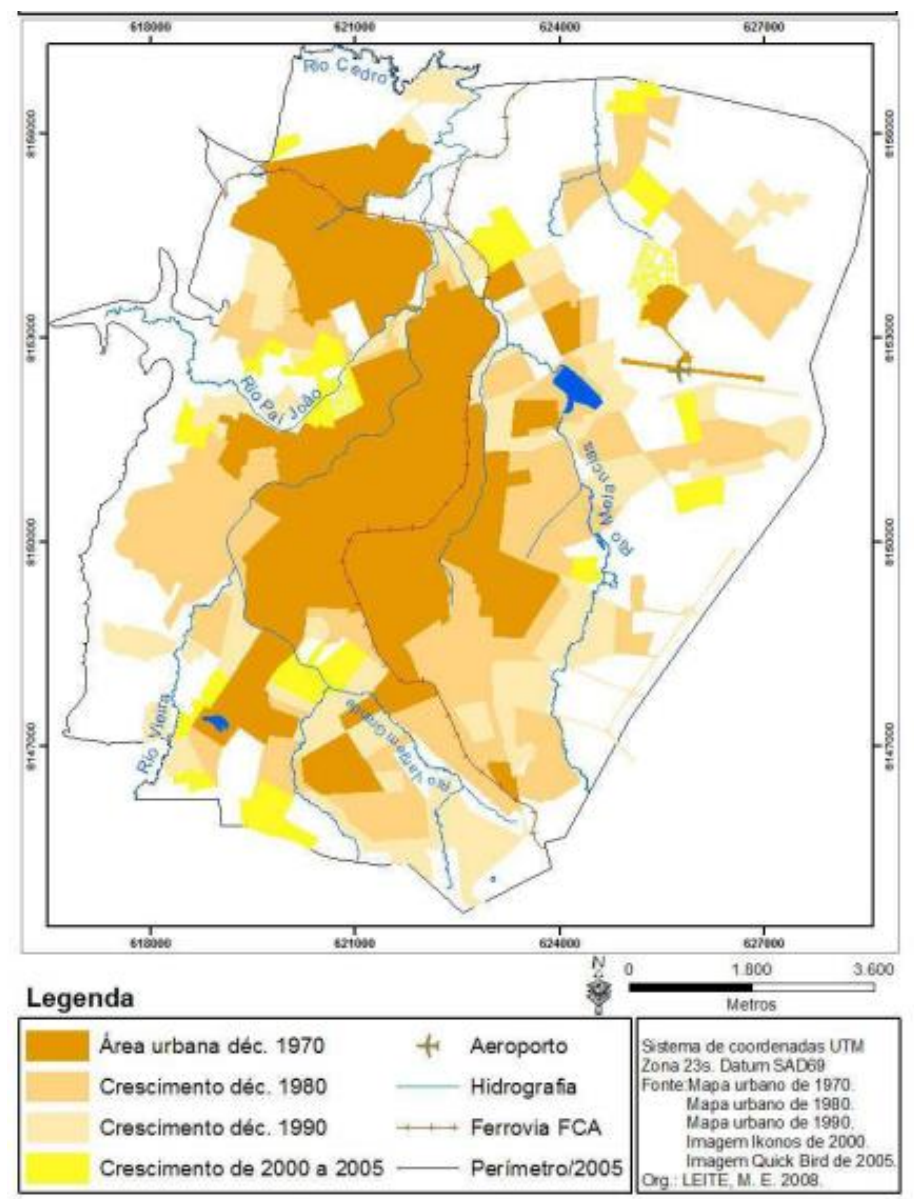

Mapa 1 - Expansão Urbana de Montes Claros de 1970 a 2005

Fonte: LEITE, 2011, p.153.

Diante do exposto, percebe-se que a desigualdade social se revela também na estruturação físico-territorial do espaço urbano de Montes Claros. A região Leste da cidade tem apresentado um intenso crescimento e é ocupada por uma população de baixo poder aquisitivo, enquanto a região Oeste é habitada por uma população de classes médias e altas, apresenta boa infraestrutura e um valor de solo urbano mais elevado. Um importante aspecto a se considerar sobre Montes Claros é que seus atributos the permitem classificar como uma cidade média. A função que desempenha para o estado de Minas Gerais, sua localização geográfica estratégica e sua capacidade de atração de pessoas, investimentos e serviços lhe atribuem tal relevância.

De acordo com a geógrafa montes-clarense lara França (2007), Montes Claros se enquadra como cidade média não apenas pelo seu tamanho, mas pelo papel regional que exerce. A cidade se apresenta como um centro regional que comanda as áreas do seu entorno com menor diversidade de funções, além de abrigar fluxos regulares de 
mercadorias, pessoas e informações, interagindo com a capital estadual, Belo Horizonte, que a polariza. O conceito de cidade média é abordado por pesquisadores brasileiros como Amorim Filho, Bueno e Abreu (1982), Spósito (2001), Soares (2005), Leite e Pereira (2017), dentre outros, que têm investigado cidade desse porte, incluindo as de Minas Gerais, dedicando seus trabalhos no sentido de compreender suas características e avançar nas reflexões teóricas e metodológicas. Em muitos desses estudos, Montes Claros é classificada como tal. Nessa direção, Spósito (2001) ressalta que

(...) pode-se caracterizar as "cidades médias" afirmando que a classificação delas, pelo enfoque funcional, sempre esteve associada à definição de seus papeis regionais e ao potencial de comunicação e articulação proporcionado por suas situações geográficas, tendo o consumo um papel mais importante que a produção na estruturação dos fluxos que definem o papel intermediário dessas cidades. (SPÓSITO, 2001, P. 635).

Para Leite e Pereira (2005), Montes Claros é considerada a única cidade Média no norte de Minas Gerais e se destaca no cenário regional pela força de atração que exerce sobre as demais cidades da região. Atualmente, se sobressai na oferta de serviços relacionados à educação, sobretudo os de ensino superior, e nos relacionados à saúde, incluindo os de alta complexidade. Além desses parâmetros, também se observa em Montes Claros suas formas de expansão e aglomeração urbana, as quais são indicadores de sua caracterização, conforme ressalta Spósito (2001).

Diante disso, um fenômeno que se identifica na configuração das cidades médias é a descentralização da área de ocupação inicial, originando novas centralidades, o que ocorre devido à expansão da população e consequentemente da malha urbana, associada à demanda por moradia, trabalho e consumo. Em decorrência do crescimento territorial e afastamento do centro, nas cidades grandes e médias, formam-se novos bairros e loteamentos e aponta-se para o surgimento de novos núcleos de comércio e serviço, chamados subcentros (FRANÇA, 2007). Os subcentros atendem diretamente às necessidades da população daquele entorno, atraindo empreendimentos diversificados e moradores, pela facilidade de acesso e proximidade a pontos importantes no cotidiano. Segundo França (2007), os subcentros de Montes Claros originaram-se em áreas residenciais e estão distribuídos em várias regiões da cidade, atendendo às necessidades dos moradores, embora alguns sejam considerados mais completos que os outros, com relação aos tipos de serviços ofertados. 


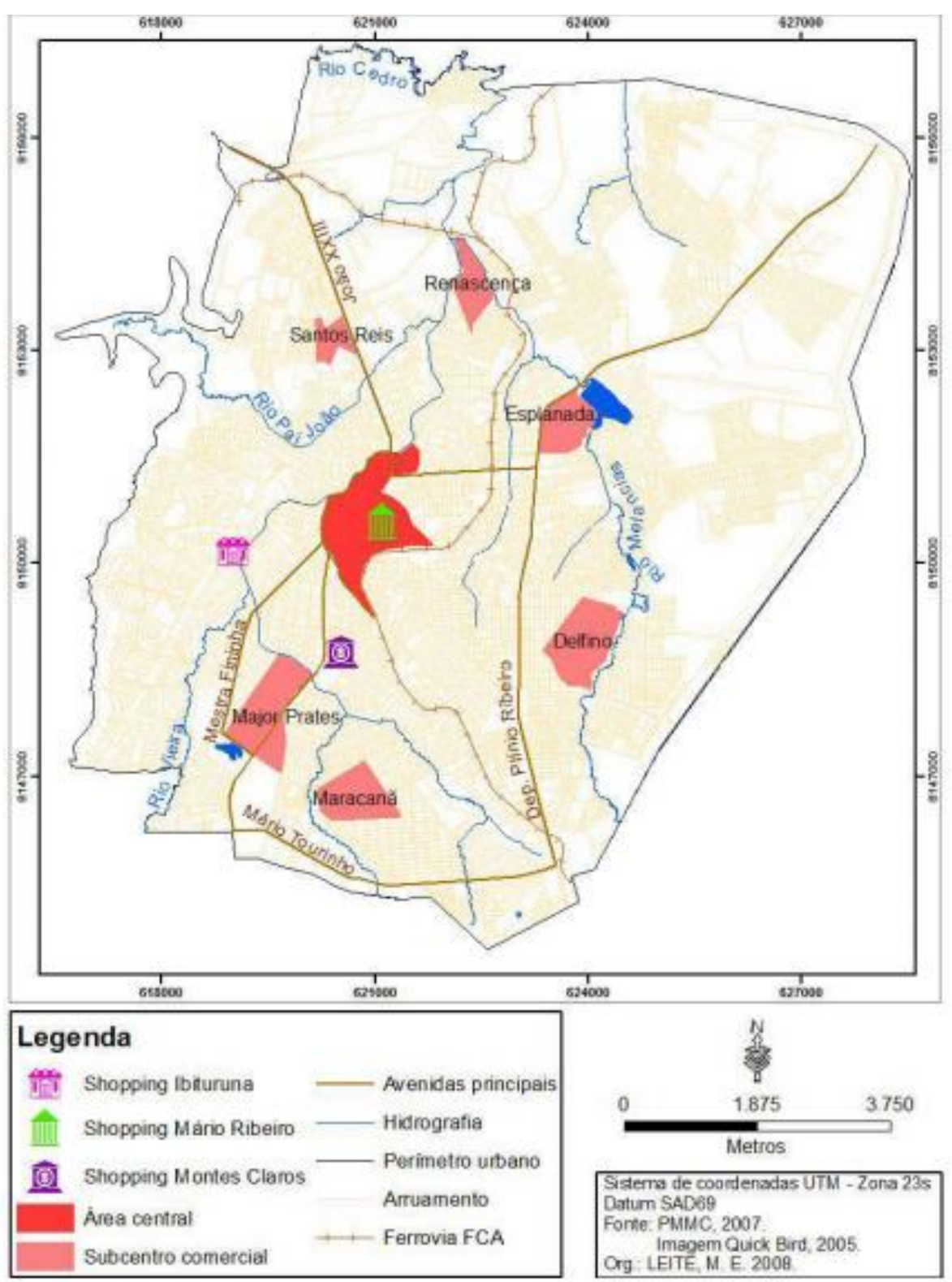

Mapa 2 - Subcentros comerciais e shopping centers da cidade de Montes ClarosMG/2008

Fonte: LEITE, 2010.

De acordo com Leite (2006), a dinâmica de Montes Claros fez com que os subcentros comerciais se formassem nas periferias da malha urbana. O Mapa 2 demonstra a localização dos seis bairros que se destacam como polos comerciais Delfino, Esplanada, Maracanã, Major Prates, Renascença e Santos Reis -, sendo o bairro Major Prates considerado o mais completo, pela variedade de serviços oferecidos, que inclui um Posto de Saúde Municipal, uma Delegacia Regional de Segurança Pública, escolas e faculdades e serviços bancários. 


\section{ONDE ENTRA O PLANEJAMENTO}

O Planejamento urbano é um termo abrangente, que envolve diferentes estratégias de direcionamento das políticas e regras que serão impostas a uma cidade ou região. De forma geral, no Brasil, o planejamento se expressa, principalmente, por meio do Estatuto da Cidade, Lei no 10.257, de 10 de julho de 2001, que "estabelece normas de ordem pública e interesse social que regulam o uso da propriedade urbana em prol do bem coletivo, da segurança e do bem-estar dos cidadãos, bem como do equilíbrio ambiental". (BRASIL, 2002, p.17) O mesmo Estatuto determina que o plano diretor, aprovado pela Câmara Municipal, obrigatório para cidades com mais de vinte mil habitantes, é o instrumento básico da política de desenvolvimento e de expansão urbana, afirmando que "A propriedade urbana cumpre sua função social quando atende às exigências fundamentais de ordenação da cidade expressas no plano diretor, assegurando o atendimento das necessidades dos cidadãos quanto à qualidade de vida, à justiça social e ao desenvolvimento das atividades econômicas, respeitadas as diretrizes previstas no art. $2 \circ$ desta Lei." (BRASIL, 2002, p.32)

Em conjunto, Estatuto da cidade e Plano Diretor estabelecem políticas a serem aplicadas nas cidades, utilizando-se de um discurso bem articulado e convincente, atendendo às reivindicações que vinham sendo feitas pelos movimentos sociais que lutavam pela reforma urbana. O texto do Estatuto foi considerado um grande avanço, abrindo um caminho de esperança no início dos anos 2000, trazendo princípios como a "função social da cidade e da propriedade", como a participação popular nas decisões, gestão democrática de cidade, instrumentos que submetem a propriedade privada aos interesses coletivos, dentre outros.

A partir do discurso técnico e racional por parte dos planejadores, desenvolvese o processo de acumulação e de alienação da população. Para Carlos,

a extensão do capitalismo, na escala nacional, realizou a generalização do espaço sob a forma de propriedade privada, criando a contradição entre o espaço produzido enquanto valor de uso (destinado à realização da vida) e o espaço produzido enquanto valor de troca (a produção do espaço voltada à realização da economia) e, nessa última condição, a cidade é ora força produtiva ora possibilidade de ser consumida produtivamente. (CARLOS, 2014, p.27) 
Com isso, os cidadãos ficam presos a um universo de consumo e se submetem ao tipo de relação característico dele, logo, cidade e sociedade atuam como extensão do mundo da mercadoria, destruindo, assim, o sentido criado pelas pessoas, pelas interações sociais, memórias, apropriações, ou seja, aquilo que forma a identidade. Os limites e barreiras se tornam cada vez mais intransponíveis, em forma de viadutos, pontes, muros de condomínios, fachadas cegas e guaritas, enfraquecendo ou mesmo inviabilizando as relações de vizinhança e sociabilidade.

Nesta direção, faz-se urgente e necessária uma crítica ao pensamento que simplifica a compreensão da cidade e acredita na promessa do planejamento urbano como única solução possível para os diversos conflitos e desigualdades que se sobrepõem ao espaço construído. As tessituras urbanas fragmentadas e segregadas levam a crer que não há uma "ausência" de planejamento urbano, mas pelo contrário, há um Planejamento que trabalha para manter a lógica perversa das cidades contemporâneas.

Randolf (2014, p.51) elucida que o planejamento seria uma "racionalização da racionalização", e que expressa, dessa maneira, os imperativos de uma lógica instrumental-abstrata que retrata exatamente esse mesmo caráter (abstrato) das esferas da sociedade - economia e burocracia do Estado - responsáveis pela sua formulação. Para o autor, é um princípio do planejamento impor essa racionalidade da lógica instrumental, seja da mercadoria, ou da burocracia, nas esferas que ainda mantêm outras formas de "integração" social. Assim, resgatando Marx e Habermas, ele constrói a argumentação de que

Este é um processo interno de permanente ampliação de relações abstratas em detrimento a formas comunicativas e concretas de convivência entre membros de uma sociedade. Nesta sua ação "colonizadora", o planejamento revela seu caráter profundamente ambíguo: é o próprio discurso de eficácia e eficiência que fornece as bases legitimadoras para a função ideológica do planejamento de propagar a lógica instrumental em esferas da vida tanto dentro como fora dos sistemas econômicos e das burocracias administrativas - assim, nessa sua face de submeter esferas fora do sistema, ele é um dos principais instrumentos de colonização das sociedades capitalistas tardias. (RANDOLF, 2014, p.51)

A relação que se pretende construir aqui é a de que o referido planejamento é desenvolvido hoje, nas cidades brasileiras, a partir da distorção dos princípios descritos 
no texto do Estatuto e dos próprios Planos Diretores. As promessas realizadas acabam se tornando discurso cooptado, mais uma vez, pelas forças econômicas e perpetuam uma maneira cínica de construir espaços urbanos. No bairro Major Prates, no entanto, esses direitos, saberes e fazeres estão constantemente em disputa. Uma disputa viva e visível quando se circula pelas ruas. Ao se construir sob os moldes do consumo e do comércio, emergem sujeitos não apenas da cidade, mas sobretudo do campo e as interações entre urbano e rural geram uma explosão cultural, permitindo análises complexas de como a pandemia está interferindo no bairro, mas também, como o bairro está interferindo na pandemia. Aqui, os espaços públicos dão um salto na sua importância e chamam a atenção para a relevância dos mesmos para a promoção da vida urbana e da saúde urbana.

\section{O BAIRRO MAJOR PRATES}

Este trabalho adotou o bairro Major Prates como área de estudo, pois representa um dos subcentros mais completos da cidade de Montes Claros, mas, ainda assim, chama a atenção de estudiosos, em função de seus aspectos culturais, os modos de agir citadinos, as estratégias dos moradores e trabalhadores ao interagir com o espaço público, além seus usos intensos e diversos. O bairro localiza-se na região sul da cidade, tendo como adjacentes os bairros Augusta Mota, Morada do Parque, Morada do Sol, São Geraldo, Vargem Grande e Canelas. Possui aproximadamente 5.279 residentes, distribuídas em uma área de $7.6 \mathrm{Km}^{2}$. (BUSTAMENTE; DURÃES, 2015)

Sendo um dos maiores adensamentos populacionais da cidade e, além de apresentar um grande mercado consumidor, o bairro foi classificado como subcentro em função de sua infraestrutura urbana, sua localização geográfica privilegiada e seu dinamismo econômico. (FRANÇA, 2010) A proximidade do bairro com o centro, cerca de quatro quilômetros, foi um fator determinante para receber tal classificação e para induzir o desenvolvimento da região sul, o que pode ser constatado na articulação do sistema viário, que conduz diariamente um grande volume de veículos e pessoas nos dois sentidos de trânsito. Vale destacar a presença da BR 365, atravessando o bairro,

que faz a interligação de Montes Claros com Pirapora, no norte de Minas e com Uberlândia, no Triângulo Mineiro. 
Ao analisar as diretrizes do Plano Diretor para o Major Prates, percebe-se que diversos trechos do bairro são classificados como Zoneamentos que privilegiam a construção de comércios, edificações com mais de dois pavimentos, e outros tipos de uso, menos comuns em bairros residenciais. Essa característica diferencia o Major Prates, no sentido de atrair uma dinâmica imobiliária mais intensa, com maior valorização dos lotes, inclusive porque apresenta muitos pontos de referência que interferem e ampliam essa valorização. Ainda assim, o bairro não demonstra um aspecto enobrecido ou luxuoso. Ao observar a arquitetura predominante nas várias ruas do bairro, ainda se encontram traços de ruralidade, de cidades pequenas. Mesmo as novas edificações, construídas nos últimos anos, adotam um estilo arquitetônico compatível com o mencionado, sem alterar significativamente o aspecto do conjunto.

Segundo o Zoneamento de Montes Claros, os trechos de Zona Residencial 2 (ZR2) são predominantes. No entanto, há outros tipos distribuídos e intercalados ao longo de seu limite. Ao todo, apresenta sete zonas diferentes, sendo elas Setor Especial 2 (SE2); Setor especial 3 (SE-3); Zonas residenciais 1, 2 e 3 (ZR-1, ZR-2 e ZR-3) e Zonas Comerciais 1 e 2 (ZC-1 e ZC-2). Os trechos de uso mais intenso coincidem com zoneamentos mais permissivos. Por exemplo, as Avenidas Castelar Prates, Olímpio Prates e Pompéia são Zona Residencial 3 (ZR-3); A Avenida Francisco Gaetani é Zona Comercial 2 (ZC-2); A Avenida Pedro Augusto Veloso apresenta um trecho como ZR-2 e outro como ZR-3.

Ainda dentro do bairro, estão inseridas duas áreas que se destacam. O Parque Municipal Milton Prates, principal parque do município, que é classificado como Setor Especial 2 (SE-2); A leste do Parque, um grande loteamento foi inaugurado em 2017, ainda pouco edificado (apenas pelo supermercado Mart Minas), e é classificado como Zona Residencial 1 (ZR-1). Uma pequena porção à leste é classificada como SE-3, que corresponde a um espaço destinado ao desenvolvimento de projetos especiais relacionados ao transporte, segundo a Prefeitura Municipal de Montes Claros (2009). A Av. Doutor Mário Tourinho, limite sul do bairro e um trecho que interliga com a Av Mestra fininha são classificadas como ZC-1. As referidas avenidas Francisco Gaetani e Castelar Prates, além de principais acessos ao bairro, concentram a maior parte das instituições, dos comércios e serviços do bairro, formando um ponto nodal onde se 
cruzam e atraindo diariamente um grande contingente de pedestres, bens e transportes.

Atualmente podem ser encontradas lojas de vestuário e de cama, mesa e banho, eletrodomésticos, materiais de construção, academias, salões de beleza, casas lotéricas, serviços de transporte de passageiros e de carga, oficinas mecânicas, farmácias, hotéis, creches, dentre outras atividades, que demonstram o potencial econômico da região. Além dessas atividades, destacam-se a Delegacia Regional de Segurança Pública, o Posto de Saúde municipal, a Igreja Nossa Senhora da Aparecida, a faculdade Unopar, a agência do Banco Siccob e a presença de alguns bares, capazes de atrair um grande número de pessoas, durante toda a semana. Cabe ressaltar que a avenida Francisco Gaetani dá acesso ao anel rodoviário sul, que é saída para a BR 135, e faz conexão direta com o centro e com outros bairros da cidade. Logo, a proximidade com as duas BRs - 135 e 365 - fazem com que o Major Prates atue como uma área de passagem de pessoas que visitam a cidade ou passam por ela, atraindo uma maior visibilidade. Registra-se também, no bairro, a presença de templos religiosos e áreas verdes, como a Praça principal e o Parque Municipal Milton Prates, além dos diversos bares, restaurantes, lanchonetes, sorveterias e quadras de futebol society, que configuram o subcentro como um núcleo de lazer que atende, além de seus moradores, visitantes de outras regiões e distritos. Dessa forma, o Major Prates se apresenta como uma das novas centralidades da cidade, conforme elucidado anteriormente, exercendo, portanto, uma polarização na área em que está localizado. O espaço se destaca pela diversidade de serviços e equipamentos que oferece e seu alcance extrapola os limites do bairro, atingindo inclusive a população regional.

\section{OS USOS NA PANDEMIA}

Ao iniciar as reflexões, destaca-se que o recorte do estudo é feito em um momento crítico da realidade atual mundializada, em que a difusão de um vírus de alta letalidade chega ao Brasil e encontra um sistema de saúde sucateado pelas políticas neoliberais. Os números de infectados e de mortos infelizmente são alarmantes, bem como a capacidade das redes hospitalares em atender às enormes demandas. Como a 
realidade é dialética, no caso brasileiro essas crises vêm intensificar as desigualdades e a crise urbana, que já se mostrava grave. Pode-se dizer que,

No plano local, as políticas públicas direcionando os orçamentos distribuem desigualmente os recursos, precarizando a vida urbana que se faz com a privação do urbano e perda de direitos. Nesta escala, a segregação socioespacial ilumina a hierarquia social que se realiza como hierarquia espacial, impondo acessos diferenciados aos lugares da cidade, pela imposição da propriedade privada, que produz e estrutura a sociedade desigual que vivemos e que vai espelhar aonde a pandemia vai atacar mais fortemente. Esse movimento em direção ao futuro se faz em detrimento do humano - que apenas sobrevive - e, agora, também da vida. (CARLOS, 2020, p.11)

Nesse sentido, entende-se que para alguns, privilegiados, a pandemia pode ser evitada com o isolamento social, para outros, o isolamento não foi possível, uma vez que os mais despossuídos precisaram se ajustar ao novo cenário, com as novas regras, decretos e portarias, em busca dessa referida sobrevivência. Assim, com esse raciocínio, foram feitos alguns registros que refletem complexas informações, complexas relações entre pessoas, circulações, espaço público e trabalho. As fotos foram tiradas ao longo do mês de dezembro de 2020, na Avenida Castelar Prates, importante eixo do bairro Major Prates.

Os registros realizados durante a pandemia do Covid-19 permitem algumas interpretações e, também, extrapolações, baseadas nas experiências da autora no bairro e na cidade de Montes Claros. A figura 1 mostra um senhor se locomovendo de bicicleta, em um espaço inadequado para esse tipo de transporte, revelando um esforço de se adequar a vias que não favorecem os ciclistas, mas tão somente os automóveis. Ainda assim, o senhor se ajusta e utiliza as vias, da maneira que pode. 


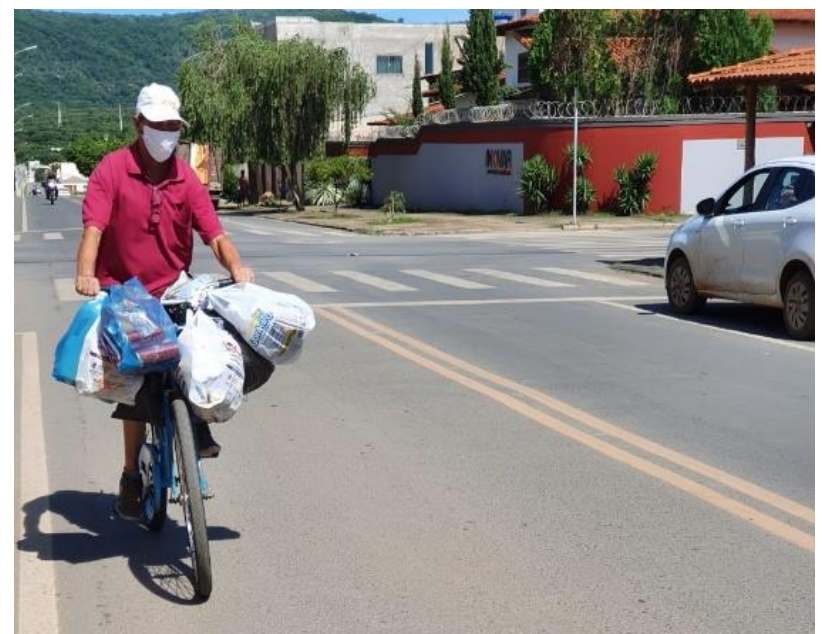

Figura 1 - Transporte por bicicleta na Av. Castelar Prates Fonte: acervo pessoal, 2020

As figuras 2 e 3 mostram um importante cruzamento do bairro, onde se encontram as principais Avenidas: Castelar Prates e Francisco Gaetani. Esse ponto é considerado um "nó", tanto viário, como de referência e concentração de funções. Nesse exato ponto geográfico, inicia-se a feira livre. Neste ano, a feira se adaptou a novas regras e configurações, mantendo um espaçamento maior entre as barracas, com uma menor quantidade de unidades, sem o toldo que fechava a via, criando dois corredores no centro da avenida. Também se pode perceber uma quantidade de feirantes e visitantes utilizando máscaras (uns de maneira correta, outros incorretamente), e a presença de funcionários da saúde, aspergindo álcool nas mãos dos transeuntes. Claramente esvaziada, a feira resiste.

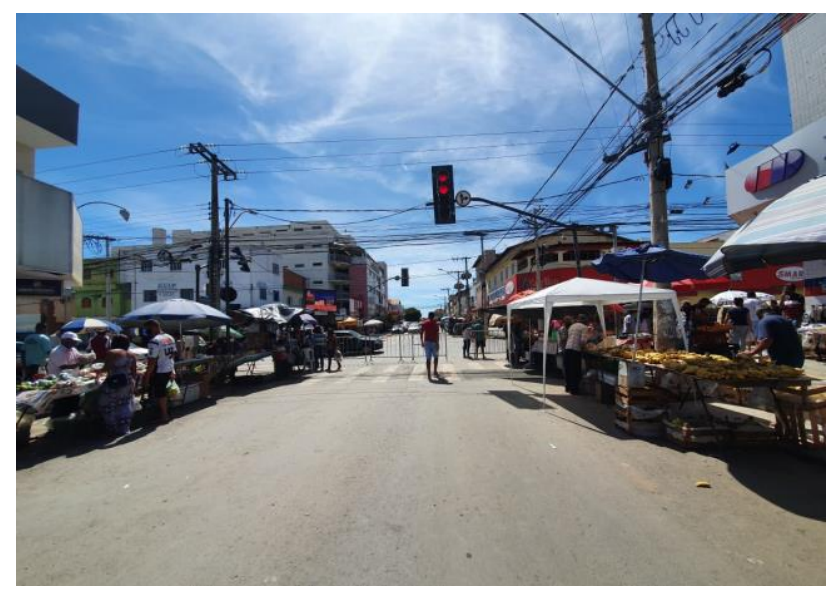

Figura 2 - Novo arranjo das barracas da feira dominical na Av. Castelar Prates 


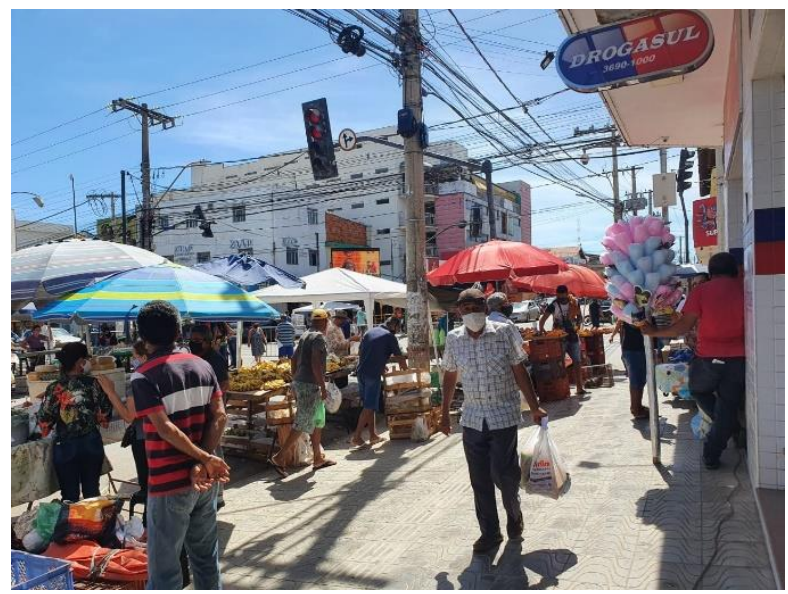

Figura 3- Cruzamento da Av. Castelar Prates com Av. Francisco Gaetani Fonte: acervo pessoal, 2020

A figura 4 refere-se a uma esquina da Avenida Castelar Prates, em que se localiza o bar Whisky Zito, ponto de encontro e de referência durante a semana e aos finais de semana. Nas manhãs de domingo, assumem um caráter ainda mais marcante, em função de estar muito próximo da feira. Neste ponto, observam-se pessoas sem máscara, o que se justifica pelo consumo de bebidas e alimentos. Logo, pode-se afirmar que o funcionamento do bar foi menos afetado pela pandemia, já que continua sendo utilizado com ocupação razoável durante todos os dias da semana.



Figura 4 - Bares com mesas na calçada Fonte: acervo pessoal, 2020

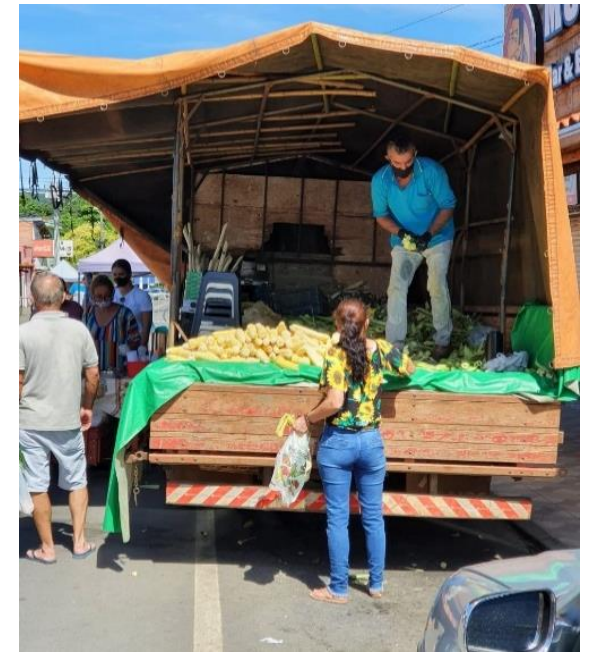

Figura 5 - Apoios da feira Fonte: acervo pessoal, 2020

Um dos aspectos que se destaca na feira é a maneira que as pessoas se apropriam da rua, criando novos arranjos espaciais, criando micro-territórios com seus 
pertences, caixas, veículos e produtos. A figura 5 mostra um dos feirantes descascando milho dentro de um caminhão. É possível abstrair que o objeto seja um veículo, pois nesse momento, ele atua como um imóvel, um ambiente construído. Também se percebem mais mobiliários conformando outros ambientes, em frente ao caminhão, como um balcão de atendimento e exposição de mercadoria.

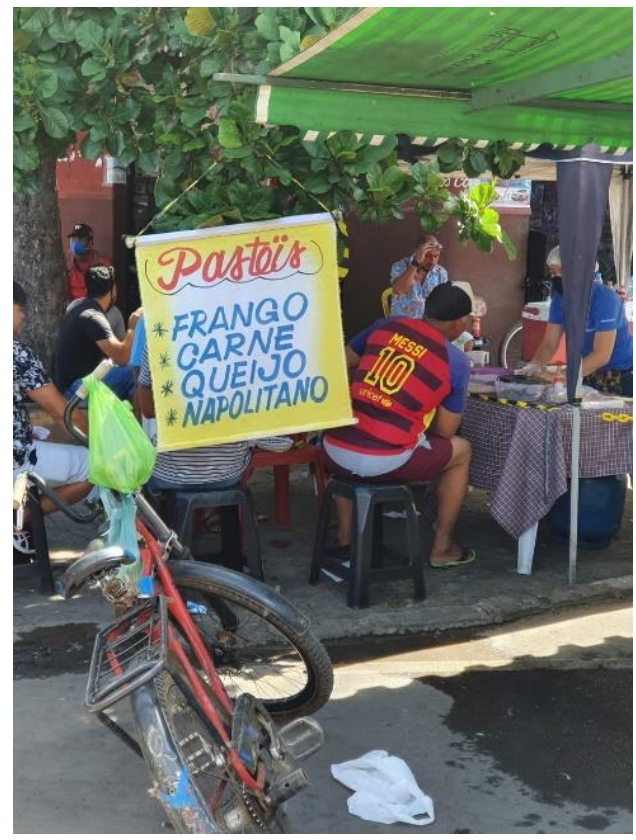

Figura 6 - Espaços de socialização Fonte: acervo pessoal, 2020

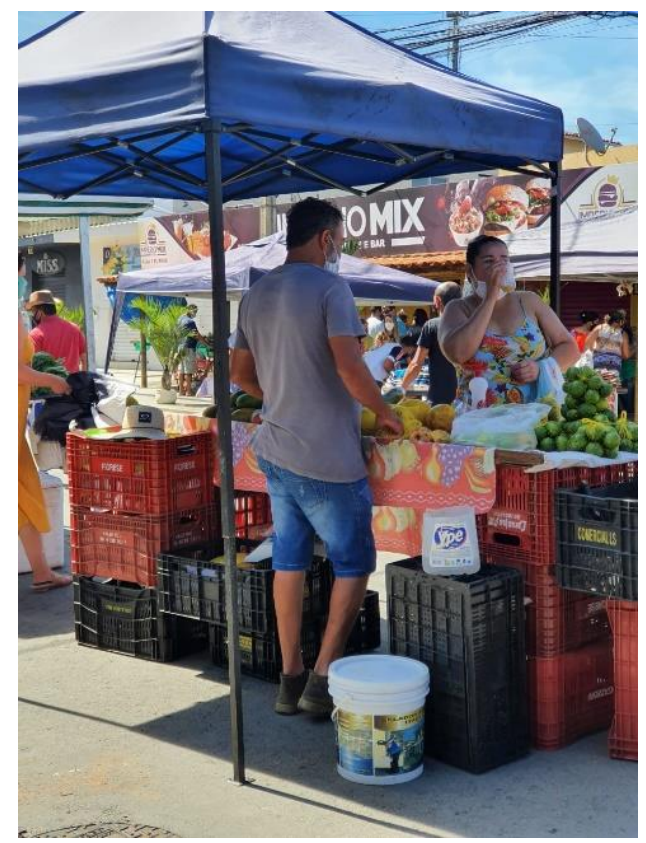

Figura 7 - Espaços de socialização Fonte: acervo pessoal, 2020

Nessa mesma direção, as imagens 6 e 7 registraram momentos de encontros em que duplas ou grupos conversavam, descontraidamente, consumindo algum produto da feira, utilizando mobiliários improvisados. Tais momentos são valiosos, ilustram o universo de possibilidades que se abre, enquanto a rua está disponível para a apropriação. Aqui, considera-se que a urbanidade é construída a partir do consumo, mas muito além dele. $\mathrm{O}$ comércio se comporta como atrativo, mas o que sobressaem são os contatos, a liberdade de circular ao ar livre, ver e ser visto, viver a festa à que Lefebvre (1999) se refere.

Em “A Revolução Urbana”, Lefebvre analisa a transição da cidade política para a cidade mercantil, do século XIV, e embora o contexto seja diverso, suas descrições se aproximam do vivenciado no bairro, não apenas na feira, mas nos dias comuns:

[...] a praça do mercado torna-se central. Ela sucede, suplanta, a praça da reunião (a ágora, o fórum). Em torno do mercado, tornado essencial, 
agrupam-se a Igreja, a prefeitura (ocupada por uma oligarquia de mercadores), com sua torre ou seu campanário, símbolo de liberdade. Devese notar que a arquitetura segue e traduz a nova concepção da cidade. 0 espaço urbano torna-se o lugar do encontro das coisas e das pessoas, da troca. Ele se ornamenta dos signos dessa liberdade conquistada, que parece a Liberdade. (LEFEBVRE, 1999, p.22)

A praça se torna metáfora para a rua. A Igreja está presente, quando os fiéis saem da missa e permanecem nas calçadas, conversando e socializando. A prefeitura, indiretamente, é representada nas instituições municipais e assim, se pode entender o bairro como um rico laboratório social. Em 2006, Fernandes se referiu ao fenômeno, dizendo:

noto que a Feira do Major Prates é um espaço privilegiado no urbano para buscar compreender a interação das populações de origem rural que estabelecem seus vínculos sociais, a partir dos valores que dão significação às suas vidas. Nesse espaço semanal não se trocam apenas mercadorias ou se estabelecem apenas relações monetárias. Nele é possível ler as estratégias que vinculam populações rurais e urbanas, ao mesmo tempo em que se deve procurar compreender a resistência e a adesão, a moral e a ação política, a troca comercial e o circuito da dádiva, distinta do individualismo, porque é baseada na reciprocidade. (FERNANDES, 2006, p. 36)

Hoje, quinze anos depois do estudo realizado por Fernandes, percebe-se que a feira continua oferecendo um espaço multifacetado, que transforma o espaço geográfico (destinado aos automóveis) e se converte em grande praça.

Ao mesmo tempo em que se submete à lógica comercial, sendo fonte de sustento de diversas famílias, coloca em risco os corpos dos trabalhadores que dependem dessa fonte de renda, mas torna-se um palco aberto de encontros, conversas, comidas, bebidas, urbanidade e vivacidade. Ao longo desses anos, não mudou a importância da feira, mas mudaram os contextos, e hoje ela se encontra num momento crítico, histórico e sem precedentes.

\section{CONSIDERAÇÕES FINAIS}

A partir das apreensões do campo, no caso, algumas avenidas do bairro Major Prates, e da aproximação com os autores, surgiram novas inquietações, que por sua vez 
abrirão caminho para novos desdobramentos dessa pesquisa, nesse momento muito embrionária. A impressão que se delineia após as observações é de que, apesar das ações que se realizam na rua, no espaço público e nos edifícios serem, de certa forma, programadas, regidas por determinadas normas e regras, formais ou intuitivas, os citadinos encontram maneiras de agir de forma inesperada, com ações não programadas, sobretudo nas maneiras de personalizar esses ambientes. Essas ações carregam mensagens importantes, posicionamentos políticos, expressões de identidade.

Agier (2011, p.182), ao tratar das ruas na cidade como espaços de manifestação política, afirma que "a rua torna-se o espaço da política e também da invenção cultural. Um não vai sem o outro; indo além, devido a esse desdobramento, a manifestação de rua é já uma dimensão da cultura das cidades".

A complexidade dos ambientes dificulta definir o que é programado e o que é arte, expressão livre ou ousadia. No entanto, é justamente nesses conflitos que se encontra a riqueza da urbanidade. O espaço das ruas e dos comércios, que no dia a dia acompanha os transeuntes e trabalhadores, se torna palco de novas relações aos domingos, ou nas horas livres. Assim, as ações múltiplas que compartilham os mesmos ambientes imprimem também identidades múltiplas, funções múltiplas, sensações múltiplas.

No domingo, especificamente, a feira provoca uma forte agitação no bairro, com as dinâmicas acontecendo simultâneas - comércio nas bancas, propagandas publicitárias nos microfones das lojas fixas, artistas de rua, visitantes comendo e bebendo, produtores rurais descascando frutas, limpando frango caipira, fieis saindo da missa na Igreja Católica, crianças brincando na praça, etc.

Em outra perspectiva, apesar da quantidade de pessoas envolvidas, compartilhando trechos de chão para expor seus produtos e acomodar os clientes, há uma sensação de equilíbrio, com a predominância de uma mediação dos conflitos. Aparentemente, a partir do olhar de visitante, as pessoas dividem harmonicamente os espaços das calçadas e das ruas, muito embora não haja demarcações muito explícitas de "territórios". Teoricamente os limites dos tubos das barracas seriam o limite de ocupação para colocar mercadorias e cadeiras, mas na prática os espaços acabam se misturando, compartilhando os terrenos. 
Com isso, pode-se dizer que as próprias maneiras de fazer o bairro, seja pela linguagem e as articulações ruralizadas, pela estética das fachadas, pelos serviços oferecidos, que pouco demonstram articulação como o centro da cidade, pelo aspecto da feira, rústico e popular, atuam como resistência a um enquadramento dos moldes do comércio enobrecido.

Não se pode falar, ainda, em uma espetacularização da feira, uma vez que os principais usuários e trabalhadores são moradores do bairro ou do entorno imediato. Também não se percebe uma propaganda ou produção de discursos no sentido de atrair turistas, visitantes e investimentos. A feira e o bairro em si produzem identidades autênticas, que não foram descaracterizadas por um ordenamento excessivo e homogeneizador. Existe, no entanto, uma preocupação de que o bairro passe por um processo de higienização e gentrificação, tendo em vista a popularidade e capacidade de atração de consumidores. Nesse ponto, ao mesmo tempo que o comércio agita a vida do pequeno produtor e comerciante, trazendo movimento e vitalidade ao bairro, é justamente o que provoca o potencial econômico que pode chamar a atenção de empresas e investidores em busca de mercantilização, colocando em risco as características identitárias dos citadinos e suas formas peculiares de apropriar e comunicar.

Por fim, a contribuição que se queria fazer com esse artigo era no sentido de fomentar reflexões mais críticas sobre os espaços públicos, sobretudo sobre os múltiplos aspectos da vida urbana. É fundamental olhar para a cidade permitindo-se enxergar as camadas, as tessituras, os agentes que a realizam. A forma de interpretar a realidade atual, pandêmica e desequilibrada, precisa de bases teóricas, mas também críticas, de modo a alcançar as contradições e disputas violentas que nela se intensificam.

\section{REFERÊNCIAS}

AGIER, Michel. Antropologia da cidade: lugares, situações, movimentos. São Paulo: Terceiro Nome, 2011, p.1-44.

AMORIM FILHO, O. B., BUENO, M. E. T. e ABREU, J. F. Cidades de porte médio e o programa de ações sócio-educativo-culturais para as populações carentes do meio urbano em Minas Gerais. In: Boletim de Geografia Teorética, Rio Claro - SP, v. 2, n. 2324, 33-46, 1982. 
BRASIL. Lei no 10.257, de 10 de julho de 2001. Estatuto da Cidade e Legislação Correlata. 2. ed., atual. Brasília: Senado Federal, Subsecretaria de Edições Técnicas, 2002. 80 p.

BUSTAMANTE, P. Cares; DURÃES, P. G. Dias. O impacto da feira livre do bairro Major Prates da cidade de Montes Claros na renda dos feirantes. Revista Desenvolvimento Social, N. 14/01, p. 109-128, 2015.

CARLOS, Ana Fani. A lógica do planejamento versus a dialética do mundo. In: LIMONAD, E.; CASTRO, E. R. (Org.). Um novo planejamento para um novo Brasil? Rio de Janeiro: Editora Letra Capital. 300p. p. 25-39, 2014.

CARLOS, Ana Fani. A "revolução" no cotidiano invadido pela pandemia. In: GESP. (Org) COVID-19 e a crise urbana. São Paulo: FFLCH/USP. 3.484 Kb; PDF, 99p. p. 10-17, 2020.

COSTA, João Batista de Almeida. A Sociedade De Curral: Desenvolvimento Social Pelas figurações Sociais, Pelo Habitus e Pela organização Do Estado No Norte De Minas. Revista Argumentos, v. 16, n. 2, p. 195-236, 2 set. 2019.

FERNANDES, Daniel Mendes. O Estar-no-Entre-Meio na Feira do Major Prates e outros Espaços Sociais: Uma Etnografia sobre as Estratégias de Territorilidade de Populações Rurais em Montes Claros. 2006. 99 f. Dissertação (Mestrado em Geografia). PPGEO, Unimontes, Montes Claros, 2006.

FRANÇA, I. S. de. A cidade Média e suas Centralidades: o exemplo de Montes Claros no Norte de Minas Gerais. 2007. 240 f. Dissertação (Mestrado em Geografia). Instituto de Geografia, Universidade Federal de Uberlândia, Uberlândia, 2007.

IBGE. Censo demográfico 2010. Disponível em: <http:\|www.ibge.gov.br>. Acesso em: 13 set. 2017.

LEITE, M. Esdras. Geoprocessamento aplicado ao estudo do espaço urbano: o caso da cidade de Montes Claros/MG. 2006. 171 f. Dissertação (Mestrado em Geografia). Universidade Federal de Uberlândia. Uberlândia, 2006.

LEITE, M. Esdras. Geotecnologias aplicadas ao mapeamento do uso do solo urbano e da dinâmica da favela em cidade média: o caso de Montes Claros/MG. 2011. 288 f. Tese (Doutorado em geografia). Universidade Federal de Uberlândia, Uberlândia, 2011.

LEITE M. E.; BATISTA R. P. e CLEMENTE C. M.S. Segregação espontânea na cidade de Montes Claros/MG: Uma análise auxiliada pelo sensoriamento remoto. Revista Eletrônica do Curso de Geografia. Jataí, n.15, 2010.

LEITE, M. Esdras; PEREIRA, A. Marília. Expansão territorial e os espaços de pobreza na cidade de Montes Claros. X Encontro de Geógrafos da América Latina. São Paulo, mar. 2005.2 Disponível em: $<$ http://observatoriogeograficoamericalatina.org.mx/egal10/Geografiasocioeconomica /Geografiadelapoblacion/29.pdf>. Acesso em: 13 set. 2017.

LEFEBVRE, Henri. A revolução urbana. Belo Horizonte: Editora UFMG, 1999.

SILVA, Lindon Jonhson Dias da. A Modernidade No Sertão: A experiência do I Plano Diretor de Montes Claros na década de 1970. 2008. 99 f. Dissertação (Mestrado em desenvolvimento social) Universidade Estadual de Montes Claros, Montes Claros, 2008.

SOARES, B. R. Cidades Médias: uma revisão bibliográfica. In: ALVES, A. F.; Flávio, L. C.; SANTOS, R. A dos (Org). Espaço e Território: interpretações e perspectivas do desenvolvimento. 1. Ed. Francisco Beltrão, Paraná, 2005. V. p.273.286. 
SPOSITO, M. da E. B. As cidades médias e os contextos econômicos contemporâneos. In: SPOSITO, M. E. B. (Org.). Urbanização e cidades: perspectivas geográficas. São Paulo: Unesp; FCT, 2001. p. 609-643. 